\title{
Lewis Base Catalyzed Addition of Trimethylsilyl Cyanide to Aldehydes
}

\author{
Scott E. Denmark* and Won-jin Chung \\ Roger Adams Laboratory, Department of Chemistry, University of Illinois, \\ Urbana, Illinois, 61801
}

\section{SUPPORTING INFORMATION}

\section{Table of Contents}

General Experimental

Literature Preparations

Lewis Base Catalyzed Additions to Aldehydes

Kinetic Plots of Reaction Order with Benzaldehyde

References

CSP GC Traces

S10-S13

Represenative HMBC Spectrum of 3d

\section{General Experimental}

All reactions were performed in oven-dried $\left(140^{\circ} \mathrm{C}\right)$ or flame dried glassware under an atmosphere of dry $\mathrm{N}_{2}$ or Ar. THF, $\mathrm{CH}_{2} \mathrm{Cl}_{2}$, hexane, toluene, and diethyl ether were dried using the solvent dispensing system. The following solvents were distilled from the indicated drying agents: $\mathrm{CHCl}_{3}\left(\mathrm{P}_{2} \mathrm{O}_{5}\right)$, ethyl acetate $\left(\mathrm{K}_{2} \mathrm{CO}_{3}\right), \mathrm{CH}_{3} \mathrm{CN}\left(\mathrm{CaH}_{2}\right)$, and 1,4-Dioxane (Na). Filtration and column chromatography were performed using EM Science 230-400-mesh silica gel. Benzaldehyde, $(E)$-cinnamaldehyde, hydrocinnamaldehyde, and phenylpropagyl aldehyde were distilled under reduced pressure before use. Trimethylsilyl cyanide was used as received. For the kinetic study, TMSCN was distilled under $\mathrm{N}_{2}$. Triethylamine was distilled from $\mathrm{CaH}_{2}$ under $\mathrm{N}_{2}$. HMPA was distilled from $\mathrm{CaH}_{2}$ under reduced pressure then stored over activated $3 \AA$ molecular sieves for more than $24 \mathrm{~h}$ before use. Pyridine $N$-oxide, $N$-methylimidazole, DMF, DMSO, thiourea, tetramethylurea, triethylphosphite, $n-\mathrm{Bu}_{3} \mathrm{P}$, and HMPT were distilled under reduced pressure before use. 4-Dimethylaminopyridine (DMAP), triphenylphosphine, and 
triphenylphosphine oxide were used as received. Trimethylamine $N$-oxide was dried with benzene using Dean-Stark trap before use. (-)-Strychinine, (S)-(-)- $\alpha$-methylbenzylamine, $(1 S, 2 R)-(+)-N$-methylephedrine, (DHQD) $)_{2}$ PHAL, and (DHQ) $)_{2}$ PHAL were used as received. When the reaction was carried out in low temperature, the internal temperature was measured by Teflon-coated thermocouples.

${ }^{1} \mathrm{H}$ NMR, and ${ }^{13} \mathrm{C}$ NMR spectra were recorded on $400 \mathrm{MHz},{ }^{1} \mathrm{H}\left(100 \mathrm{MHz},{ }^{13} \mathrm{C}\right)$ spectrometers. ${ }^{1} \mathrm{H}$ and ${ }^{13} \mathrm{C}$ spectra were referenced to residual chloroform $\left(7.26 \mathrm{ppm},{ }^{1} \mathrm{H}, 77.0\right.$ $\left.\mathrm{ppm},{ }^{13} \mathrm{C}\right)$. Chemical shifts are reported in ppm. Multiplicities are indicated by s (singlet), $\mathrm{d}$ (doublet), t (triplet), q (quartet), m (multiplet) and br (broad). Coupling constants, $J$, are reported in Hertz. ${ }^{1} \mathrm{H}$ and ${ }^{13} \mathrm{C}$ NMR assignments are corroborated by $2 \mathrm{D}$ experiments (COSY, and HMBC). Spectra are available on request from denmark@scs.uiuc.edu.

Fourier transform IR analysis was performed using a ReactIR 1000 purchased from ASI Applied Systems, Inc., 8223 Cloverleaf Drive, Suite 120, Millersville, MD 21108, (410) 9873222. Reactions were monitored using a 5/8' DiComp probe fitted to an MCT detector. Acquisitions were recorded using software version 2.1a. Analytical gas chromatography (GC) was performed on a gas chromatograph equipped with a flame ionization detector and a trifluoroacetyl $\gamma$-cyclodextrin (G-TA, 30 meter, manufactured by Astec) column. The injector temperature was $225{ }^{\circ} \mathrm{C}$. The detector temperature was $300{ }^{\circ} \mathrm{C}$ with a split ratio of approximately 100:1. Analytical supercritical fluid chromatography (SFC) was performed on a Berger Instruments packed-column SFC with built-in photometric detector $(220 \mathrm{~nm})$ using Daicel Chiralpak OD column.

The preparation of phenylpropagyl aldehyde 1d followed the procedure described by Journet et. $a l .{ }^{1}$ The preparation of $N, N^{\prime}$-bis(1- $(S)$-phenylethyl)-1,2-ethylenediamino- $N, N$ '-diaza$N$ ', $N$ ',-dimethylphospholidine 9 followed the procedure described by Feringa et. al. ${ }^{2}$ The preparation of $\operatorname{bis}(N, N$-diethylamido)menthylphosphite $\mathbf{1 0}$ followed the procedure described by Merkulov et. al. $^{3}$ The preparation of 2,2'-O,O-(1,1'-binaphthyl)-O,O'-dioxo- $N, N$ dimethylphospholidine 11 followed the procedure described by Feringa et. al. ${ }^{2}$ The preparation of tri[(1R, 2S, 5R)-menthyl] phosphate 12 followed the procedure described by Kolodiazhnyi et. $a l^{4}$ 
Triethylamine Catalyzed Addition of TMSCN to Benzaldehyde. Formation of 3a.<smiles>COC(C#N)c1ccccc1</smiles>

Acetonitrile $(3 \mathrm{~mL})$ was added to the $10 \mathrm{~mL}$ ReactIR flask with magnetic stir bar under Ar. The background scan was taken. Benzaldehyde (96 $\mu \mathrm{L}, 0.942 \mathrm{mmol}$ ) and TMSCN (132 $\mu \mathrm{L}$, 0.989 mmol, 1.05 equiv) were added to the flask and the solution was stirred. The ReactIR was initialized. After the first scan, $\mathrm{Et}_{3} \mathrm{~N}(13 \mu \mathrm{L}, 0.094 \mathrm{mmol}, 0.1$ equiv) was added. The carbonyl peak of the benzaldehyde $\left(1701 \mathrm{~cm}^{-1}\right)$ was monitored in situ by ReactIR.

DMAP Catalyzed Addition of TMSCN to Benzaldehyde. Formation of 3a.

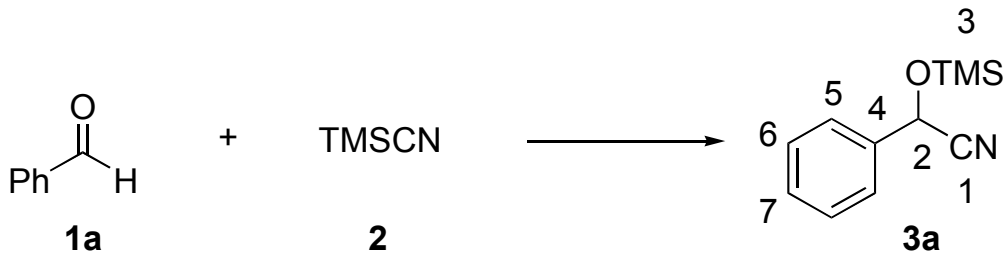

Acetonitrile $(20 \mathrm{~mL})$ was added to a flame-dried, $50 \mathrm{~mL}$ flask containing DMAP (12 mg, 0.098 mmol, 0.01 equiv) with magnetic stir bar under $\mathrm{N}_{2}$. Benzaldehyde (1 mL, $\left.9.841 \mathrm{mmol}\right)$ and TMSCN (1.325 mL, 9.939 mmol, 1.01 equiv) were added to the solution. After $1 \mathrm{~h}$, the solvent was removed under reduced pressure. The residue was purified by flash column chromatography ( silica gel, hexane/ethyl acetate, 10/1) to give $1.920 \mathrm{~g}(95 \%)$ of $\mathbf{3 a}$ as a clear, colorless oil. ${ }^{5 \mathrm{a}}$

Data for 3a:

${ }^{1} \mathrm{H}$ NMR: $\quad\left(400 \mathrm{MHz}, \mathrm{CDCl}_{3}\right)$

7.49-7.39 (m, $5 \mathrm{H}), 5.50(\mathrm{~s}, 1 \mathrm{H}), 0.24(\mathrm{~s}, 9 \mathrm{H})$

${ }^{13} \mathrm{C} \mathrm{NMR}: \quad\left(100 \mathrm{MHz}, \mathrm{CDCl}_{3}\right)$

$136.2,129.3,129.0,126.3,119.2,63.6,-0.3$

GC: $\quad$ (G-TA column, $110 \mathrm{kPa}, 90{ }^{\circ} \mathrm{C}$ )

$t_{\mathrm{R}}: 13.3 \min (50 \%), 14.3 \min (50 \%)$ 
Triethylamine Catalyzed Addition of TMSCN to (E)-Cinnamaldehyde. Formation of (3b).<smiles>CS(=O)(=O)C(C#N)/C=C/c1ccccc1</smiles>

Acetonitrile $(3 \mathrm{~mL})$ was added to the $10 \mathrm{~mL}$ ReactIR flask with magnetic stir bar under Ar. The background scan was taken. (E)-Cinnamaldehyde (119 $\mu \mathrm{L}, 0.942 \mathrm{mmol})$ and TMSCN (132 $\mu \mathrm{L}, 0.989 \mathrm{mmol}, 1.05$ equiv) were added to the flask and the solution was stirred. The ReactIR was initialized. After the first scan, $\mathrm{Et}_{3} \mathrm{~N}(13 \mu \mathrm{L}, 0.094 \mathrm{mmol}, 0.1$ equiv) was added. The carbonyl peak of the $(E)$-cinnamaldehyde $\left(1679 \mathrm{~cm}^{-1}\right)$ was monitored in situ by ReactIR.

DMAP Catalyzed Addition of TMSCN to (E)-Cinnamaldehyde. Formation of (3b).

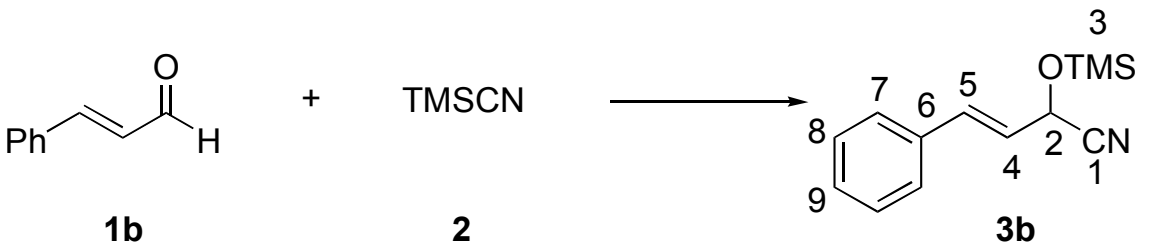

Acetonitrile $(3 \mathrm{~mL})$ was added to a flame-dried, $10 \mathrm{~mL}$ flask containing DMAP $(1.9 \mathrm{mg}$, 0.015 mmol, 0.01 equiv) with magnetic stir bar under $\mathrm{N}_{2}$. (E)-Cinnamaldehyde (192 $\mu \mathrm{L}, 1.519$ mmol) and TMSCN (205 $\mu \mathrm{L}, 1.534 \mathrm{mmol}, 1.01$ equiv) were added to the solution. After $1 \mathrm{~h}$, the solvent was removed under reduced pressure. The residue was purified by flash column chromatography ( silica gel, hexane/ethyl acetate, 10/1) to give $262 \mathrm{mg}$ (76\%) of $3 \mathbf{b}$ as a clear, colorless oil. $^{5 \mathrm{~b}, \mathrm{c}}$

Data for 3b:

${ }^{1}$ H NMR: $\quad\left(400 \mathrm{MHz}, \mathrm{CDCl}_{3}\right)$

7.43-7.31 (m, $5 \mathrm{H}), 6.82(\mathrm{dd}, J=15.8,1.0,1 \mathrm{H}), 6.20(\mathrm{dd}, J=15.5,6.0,1 \mathrm{H})$,

$5.12(\mathrm{dd}, J=6.2,1.4,1 \mathrm{H}), 0.26(\mathrm{~s}, 9 \mathrm{H})$

${ }^{13}$ C NMR: $\quad\left(100 \mathrm{MHz}, \mathrm{CDCl}_{3}\right)$

$135.0,134.0,128.8,128.7,127.0,123.5,118.4,62.2,-0.1$

GC: $\quad$ (G-TA column, $110 \mathrm{kPa}, 110^{\circ} \mathrm{C}$ )

$t_{\mathrm{R}}: 26.9 \min (50 \%), 28.1 \min (50 \%)$ 
Triethylamine Catalyzed Addition of TMSCN to Hydrocinnamaldehyde. Formation of (3c).<smiles>CS(=O)(=O)OC(C#N)CCc1ccccc1</smiles>

Triethylamine $\left(6.5 \mu \mathrm{L}, 0.047\right.$ mmol, 0.1 equiv) was dissolved in $\mathrm{CH}_{3} \mathrm{CN}$ (3mL). The solution $(30 \mu \mathrm{L})$ was added to the $10 \mathrm{~mL}$ ReactIR flask containing $\mathrm{CH}_{3} \mathrm{CN}$ (3 mL) with magnetic stir bar under Ar. The solution was cooled to $-30{ }^{\circ} \mathrm{C}$. The background scan was taken. Hydrocinnamaldehyde $(62 \mu \mathrm{L}, 0.471 \mathrm{mmol})$ was added to the flask. The ReactIR was initialized. After the first scan, TMSCN (66 $\mu \mathrm{L}, 0.495 \mathrm{mmol}, 1.05$ equiv) was added. The carbonyl peak of the hydrocinnamaldehyde $\left(1723 \mathrm{~cm}^{-1}\right)$ was monitored in situ by ReactIR at $-30{ }^{\circ} \mathrm{C}$.

\section{DMAP Catalyzed Addition of TMSCN to Hydrocinnamaldehyde. Formation of (3c).}

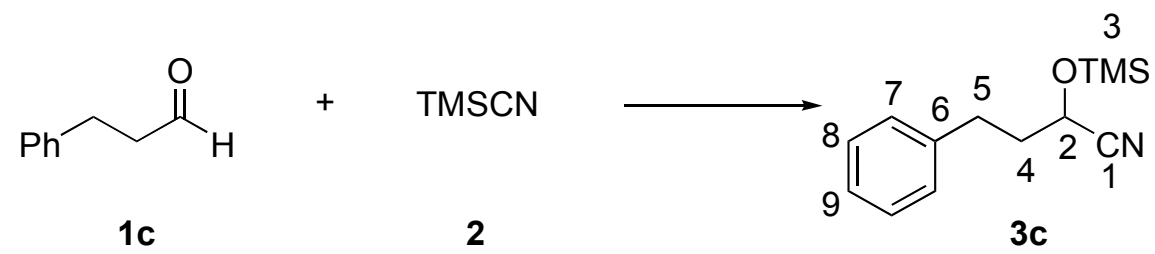

Acetonitrile $(3 \mathrm{~mL})$ was added to a flame-dried, $10 \mathrm{~mL}$ flask containing DMAP (1.9 mg, 0.015 mmol, 0.01 equiv) with magnetic stir bar under $\mathrm{N}_{2}$. Hydrocinnamaldehyde (200 $\mu \mathrm{L}, 1.519$ mmol) and TMSCN (205 $\mu \mathrm{L}, 1.534 \mathrm{mmol}, 1.01$ equiv) were added to the solution. After $20 \mathrm{~min}$, the solvent was removed under reduced pressure. The residue was purified by flash column chromatography (silica gel, hexane/ethyl acetate, 10/1) to give $301 \mathrm{mg}$ (85\%) of 3c as a clear, colorless oil. $^{5 \mathrm{a}}$

Data for 3c:

${ }^{1} \mathrm{H} \mathrm{NMR}: \quad\left(400 \mathrm{MHz}, \mathrm{CDCl}_{3}\right)$

7.33-7.19 (m, 5 H, H(Aryl)), 4.37 (dd, $J=6.4,6.4,1 \mathrm{H}), 2.80(\mathrm{dd}, J=3.8,3.8,2$

H), $2.09-2.15(\mathrm{~m}, 2 \mathrm{H}), 0.21(\mathrm{~s}, 9 \mathrm{H})$

${ }^{13} \mathrm{C} \mathrm{NMR}: \quad\left(100 \mathrm{MHz}, \mathrm{CDCl}_{3}\right)$

$139.9,128.6,128.4,126.4,119.9,60.6,37.6,30.6,-0.4$

GC: $\quad$ (G-TA column, $110 \mathrm{kPa}, 110{ }^{\circ} \mathrm{C}$ )

$t_{\mathrm{R}}: 12.5 \min (50 \%), 13.5 \min (50 \%)$ 
$\mathrm{Et}_{3} \mathbf{N}$ Catalyzed Addition of TMSCN to Phenylpropagyl Aldehyde. Formation of (3d).

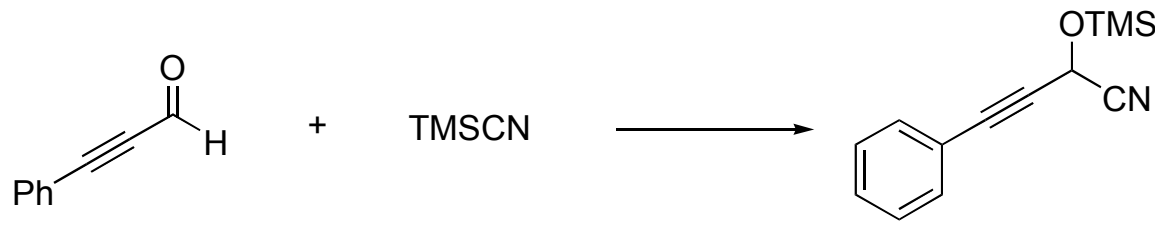

1d

2

$3 d$

Triethylamine $\left(6.5 \mu \mathrm{L}, 0.047 \mathrm{mmol}, 0.1\right.$ equiv) was dissolved in $\mathrm{CH}_{3} \mathrm{CN}(3 \mathrm{~mL})$. The solution $(30 \mu \mathrm{L})$ was added to the $10 \mathrm{~mL}$ ReactIR flask containing $\mathrm{CH}_{3} \mathrm{CN}$ ( $3 \mathrm{~mL}$ ) with magnetic stir bar under Ar. The solution was cooled to $-30{ }^{\circ} \mathrm{C}$. The background scan was taken. Phenylpropagyl aldehyde (58 $\mu \mathrm{L}, 0.471 \mathrm{mmol}$ ) was added to the flask. The ReactIR was initialized. After the first scan, TMSCN (66 $\mu \mathrm{L}, 0.495 \mathrm{mmol}, 1.05$ equiv) was added. The carbonyl peak of the phenylpropagyl aldehyde $\left(1661 \mathrm{~cm}^{-1}\right)$ was monitored in situ by ReactIR at $30{ }^{\circ} \mathrm{C}$.

DMAP Catalyzed Addition of TMSCN to Phenylpropagyl Aldehyde. Formation of (3d).

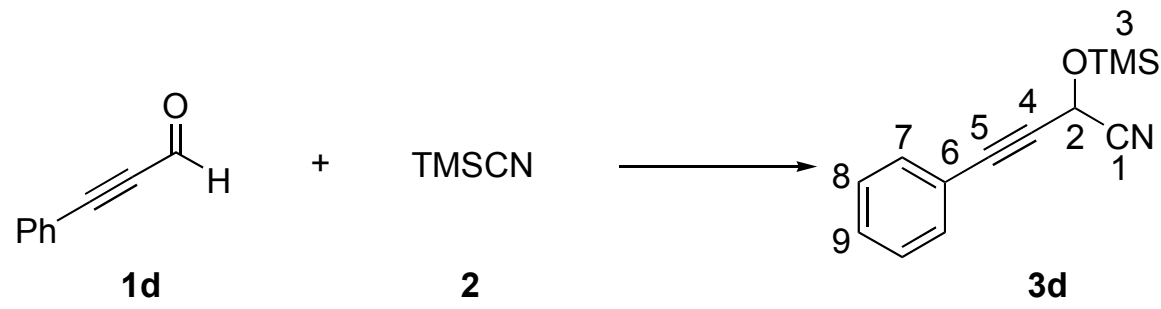

Acetonitrile (3 mL) was added to a flame-dried, $10 \mathrm{~mL}$ flask containing DMAP (1.9 mg, 0.015 mmol, 0.01 equiv) with magnetic stir bar under $\mathrm{N}_{2}$. Phenylpropagyl aldehyde (185 $\mu \mathrm{L}$, $1.519 \mathrm{mmol})$ and TMSCN (205 $\mu \mathrm{L}, 1.534 \mathrm{mmol}, 1.01 \mathrm{equiv})$ were added to the solution. After $10 \mathrm{~min}$, the solvent was removed under reduced pressure. The residue was purified by flash column chromatography ( silica gel, hexane/ethyl acetate, 10/1) to give $153 \mathrm{mg}(44 \%)$ of $\mathbf{3 d}$ as a yellow oil. ${ }^{5 b}$

Data for 3d:

${ }^{1} \mathrm{H}$ NMR: $\quad\left(400 \mathrm{MHz}, \mathrm{CDCl}_{3}\right)$

7.49-7.35 (m, $5 \mathrm{H}, \mathrm{H}($ Aryl)), 5.48 (s, $1 \mathrm{H}, \mathrm{HC}(2)), 0.31$ (s, $\left.9 \mathrm{H}, \mathrm{H}_{3} \mathrm{C}(3)\right)$

${ }^{13} \mathrm{C} \mathrm{NMR}: \quad\left(100 \mathrm{MHz}, \mathrm{CDCl}_{3}\right)$

132.2 (C(7)), 129.9 (C(9)), $128.7(\mathrm{C}(8)), 121.1(\mathrm{C}(6)), 116.6(\mathrm{C}(1)), 87.4(\mathrm{C}(5))$, $81.7(\mathrm{C}(4)), 52.3(\mathrm{C}(2)), 0.3(\mathrm{C}(3))$

GC: $\quad\left(\mathrm{G}-\mathrm{TA}\right.$ column, $\left.110 \mathrm{kPa}, 110^{\circ} \mathrm{C}\right), \mathrm{t}_{\mathrm{R}}: 22.9 \min (50 \%), 23.8 \min (50 \%)$ 
(DHQ) 2 PHAL Catalyzed Addition of TMSCN to Benzaldehyde. Formation of (3a).

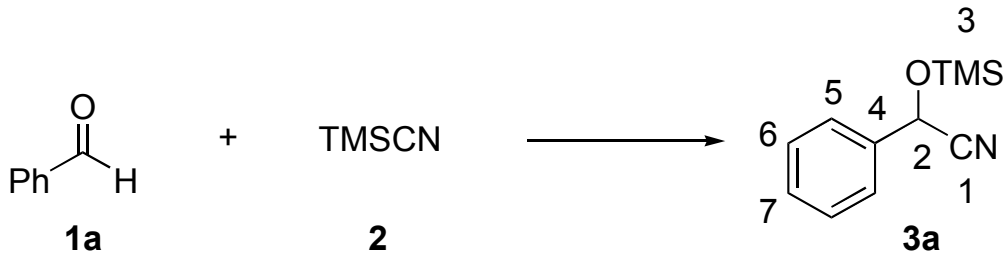

(DHQ) $)_{2}$ PHAL (18.3 mg, $0.235 \mathrm{mmol}, 0.05$ equiv) was added to a $4 \mathrm{~mL}$ vial with magnetic stir bar. $\mathrm{CH}_{2} \mathrm{Cl}_{2}$ (1.5 mL, degassed with Ar for $\left.10 \mathrm{~min}\right)$ was added to the vial under Ar and the solution was stirred. Benzaldehyde (48 $\mu 1,0.471 \mathrm{mmol})$ and TMSCN (66 $\mu 1,0.495$ mmol, 1.05 eq.) were added to the solution. After $5 \mathrm{~h}$, the reaction mixture was filtered through silica gel to remove the catalyst, and concentrated in vacuo. Enantiomeric excess was measured by GC.

Data for 3a:

GC: $\quad$ (G-TA column, $\left.110 \mathrm{kPa}, 90{ }^{\circ} \mathrm{C}\right)$

$t_{\mathrm{R}}: 13.2 \min (40 \%), 14.1 \min (60 \%)$

(DHQ) 2 PHAL Catalyzed Addition of TMSCN to (E)-Cinnamaldehyde. Formation of (3b).

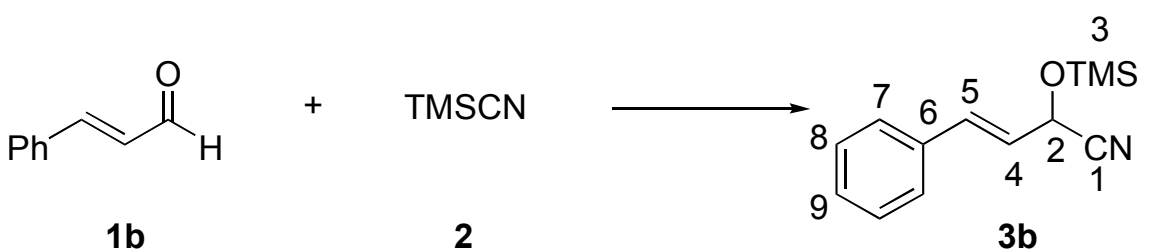

(DHQ) 2 PHAL ( $9.2 \mathrm{mg}, 0.012 \mathrm{mmol}, 0.05$ equiv) was added to a $4 \mathrm{~mL}$ vial with magnetic stir bar. $\mathrm{CH}_{2} \mathrm{Cl}_{2}(1.5 \mathrm{~mL}$, degassed with $\mathrm{Ar}$ for $10 \mathrm{~min})$ was added to the vial under $\mathrm{Ar}$ and the solution was stirred. (E)-Cinnamaldehyde (30 $\mu 1,0.236 \mathrm{mmol})$ and TMSCN (33 $\mu 1,0.248 \mathrm{mmol}$, 1.05 eq.) were added to the solution. After $18 \mathrm{~h}$, the reaction mixture was filtered through silica gel to remove the catalyst, and concentrated in vacuo. Enantiomeric excess was measured by SFC.

Data for 3b:

SFC: $\quad$ (OD column, $1.0 \% \mathrm{CH}_{3} \mathrm{OH}, 3 \mathrm{~mL} / \mathrm{min}, 125 \mathrm{bar}$ )

$t_{\mathrm{R}}: 2.9 \min (52 \%), 3.3 \min (48 \%)$ 
(DHQ) 2 PHAL Catalyzed Addition of TMSCN to Hydrocinnamaldehyde. Formation of (3c).

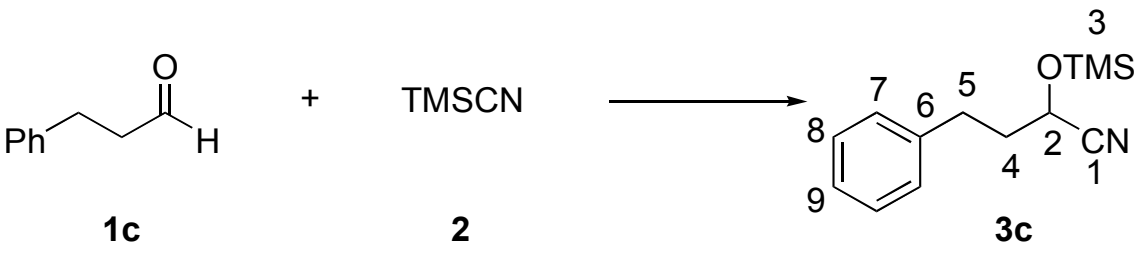

(DHQ) 2 PHAL ( $9.2 \mathrm{mg}, 0.012 \mathrm{mmol}, 0.05$ equiv) was added to a $4 \mathrm{~mL}$ vial with magnetic stir bar. $\mathrm{CH}_{2} \mathrm{Cl}_{2}(1.5 \mathrm{~mL}$, degassed with $\mathrm{Ar}$ for $10 \mathrm{~min})$ was added to the vial under $\mathrm{Ar}$ and the solution was stirred. Hydrocinnamaldehyde (31 $\mu \mathrm{l}, 0.236 \mathrm{mmol})$ and TMSCN (33 $\mu 1,0.248$ mmol, 1.05 eq.) were added to the solution. After $1.5 \mathrm{~h}$, the reaction mixture was filtered through silica gel to remove the catalyst and concentrated in vacuo. Enantiomeric excess was measured by $\mathrm{GC}$.

Data for 3c:

GC: $\quad\left(\mathrm{G}-\mathrm{TA}\right.$ column, $\left.110 \mathrm{kPa}, 110^{\circ} \mathrm{C}\right), t_{\mathrm{R}:} 10.6 \min (45 \%), 11.8 \min (55 \%)$

Kinetic Plots for ReactIR Studies with Benzaldehyde.

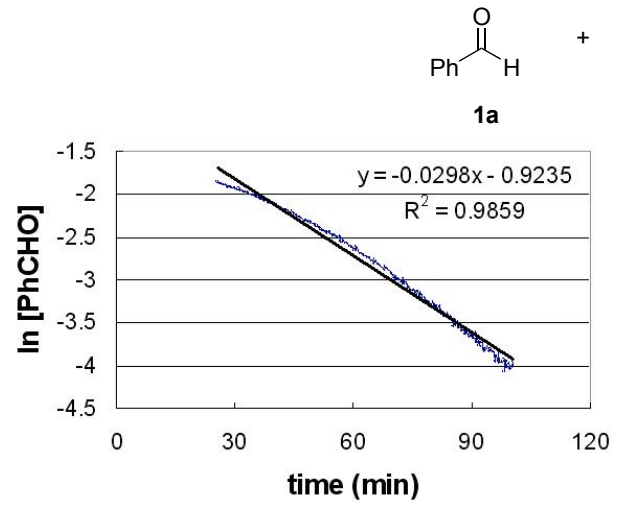

Figure 1. Overall reaction order.

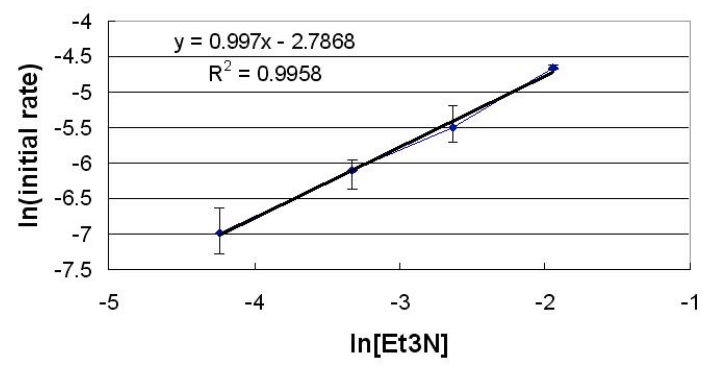

Figure 3. Order in triethylamine
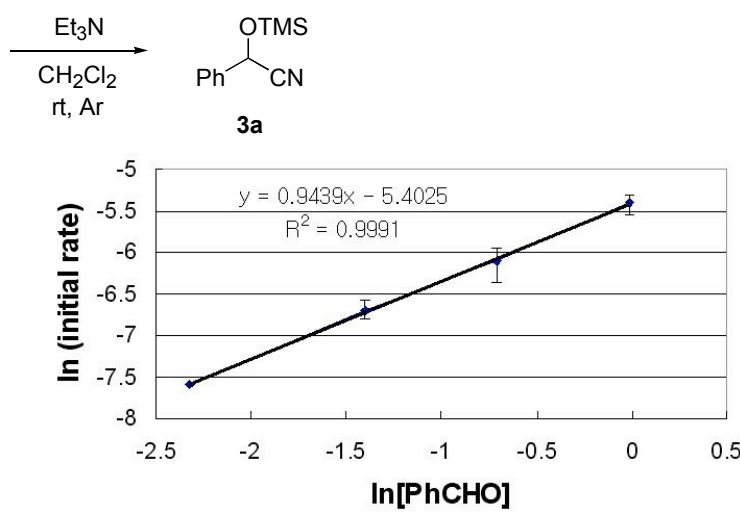

Figure 2. Order in benzaldehyde

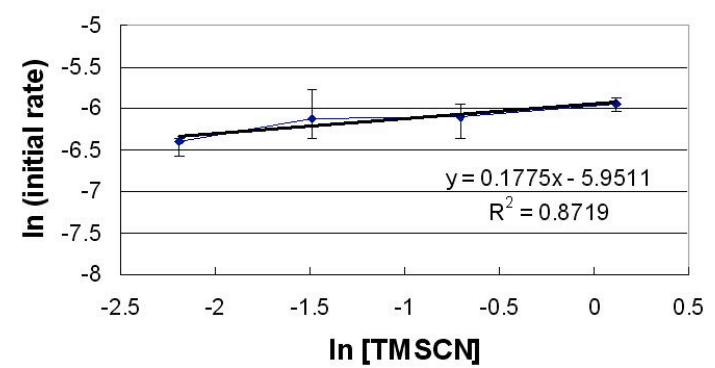

Figure 4. Order in trimethylsilyl cyanide 


\section{References}

(1) Journet, M.; Cai, D.; DiMichele, L. M.; Larsen, R. D. Tetrahedron lett. 1998, 39, 6427-6428.

(2) Hulst, R.; de Vries, N. K.; Feringa, B. L. Tetrahedron: Asymmetry 1994, 5, 699-708.

(3) Merkulov, R. V.; Maslennikova, V. I.; Nifant'ev, E. E. Russ. J. Gen. Chem. 1998, 68, 876.

(4) Kolodiazhnyi, O. I.; Sheiko, S.; Grishkum, E. V. Heteroatom Chem. 2000, 11, 138143

(5) (a) Yang, W.-B.; Fang, J.-M. J. Org. Chem. 1998, 63, 1356-1359. (b) Härle, H.; Jochims, J. C. Chem. Ber. 1986, 119, 1400-1412. (c) Kuse, M.; Isobe, M. Tetrahedron 2000, 56, 2629-2639. 


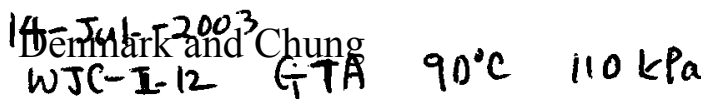

* Fiju î $19 i$

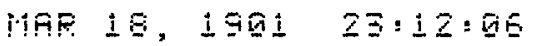

\section{START}

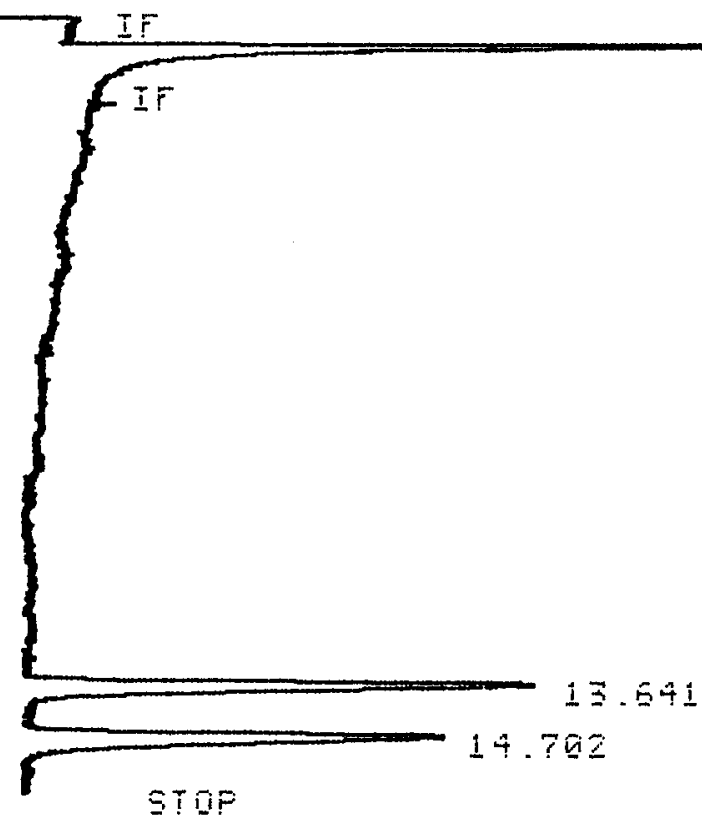

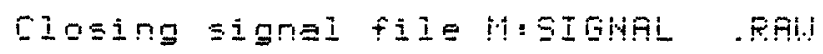

Finiti $\mathbf{1} 9 \mathbf{i}$

MFR Iฐ, I\$QI

$25: 12: 05$

$P h \stackrel{\text { OTMS }}{\mathrm{L} C \mathrm{~N}}$ racemic

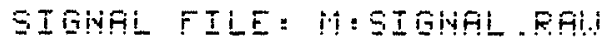

AREAY:

RT FREF TYPE IIITH AREF\%

IE.641 430? BP .209 49.78614

$14.702 \quad 4344$ Ei $256 \quad 50.21384$

TOTPL AREF= 8651

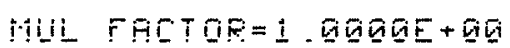




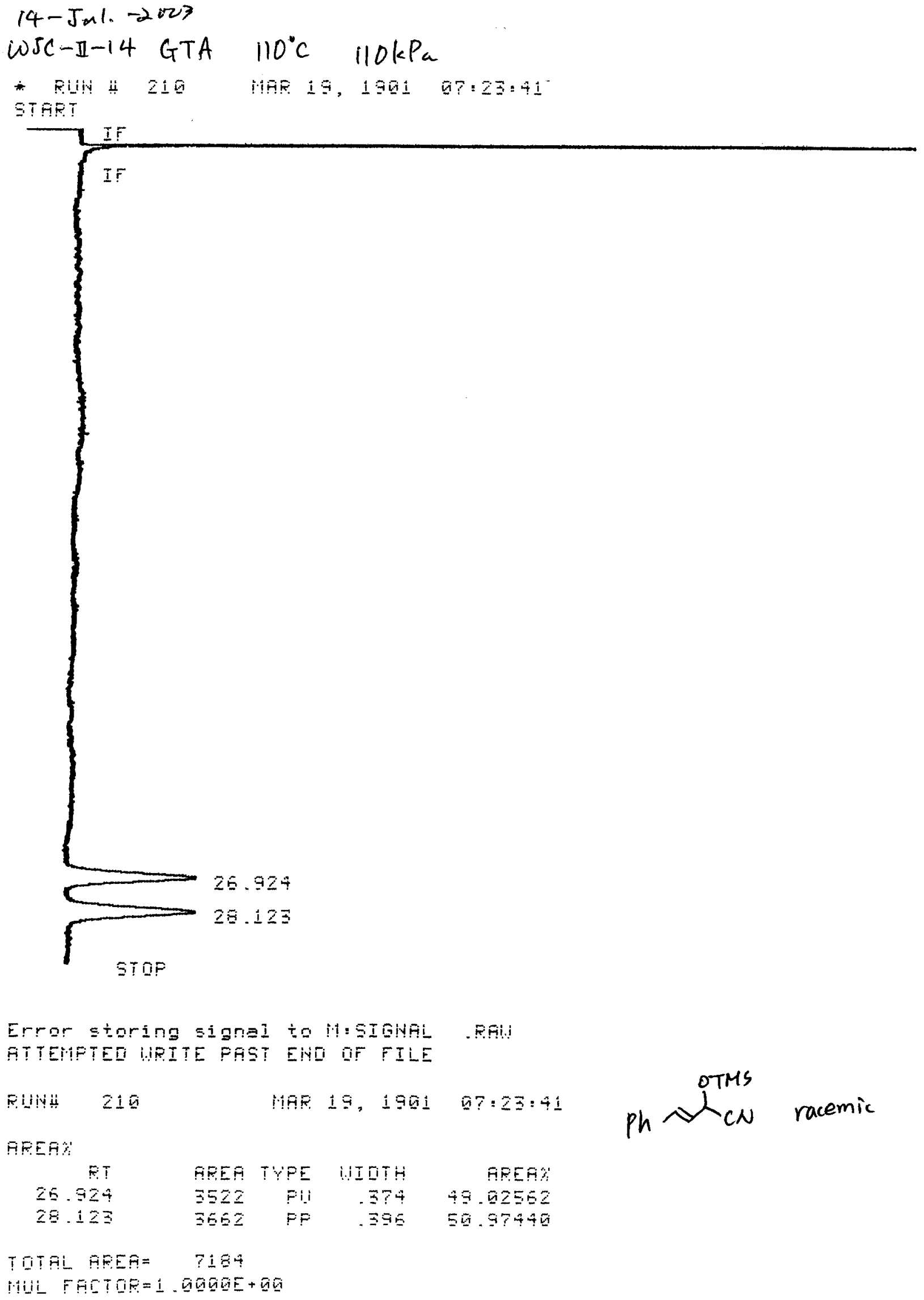


$|4-J u|=-2003$

WJ C $-11-13$ GTA $110^{\circ} \mathrm{C} \quad 110 \mathrm{kPa}$

S12

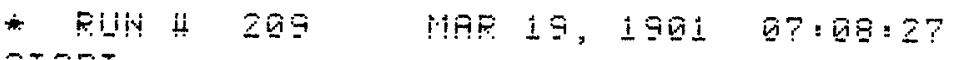

START

LIF

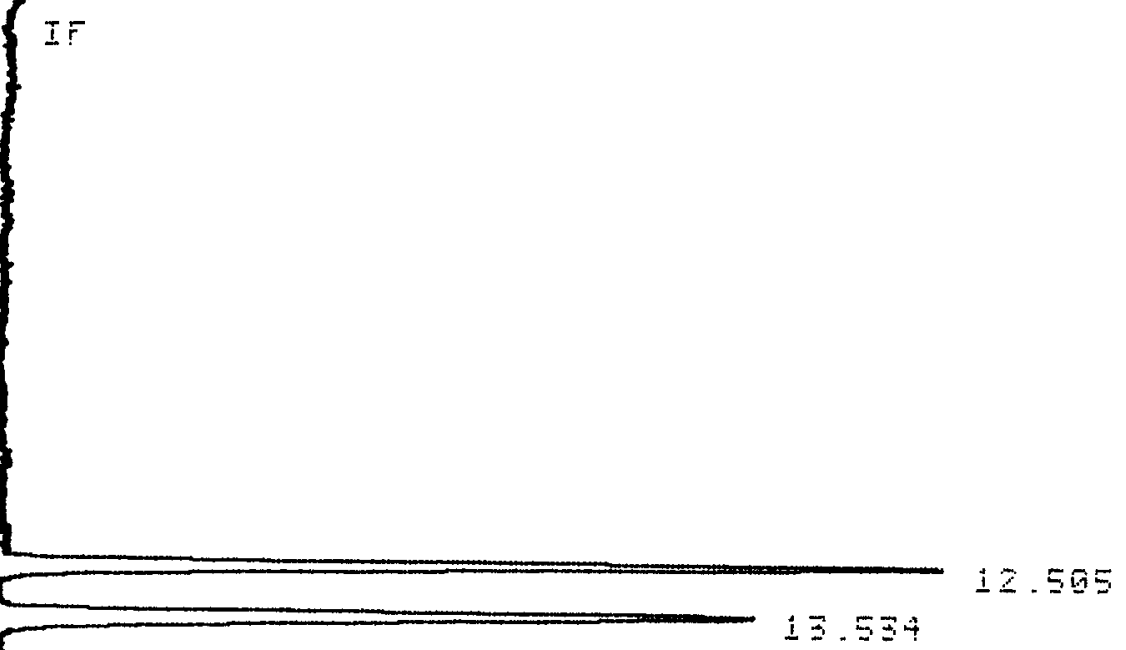

STOF

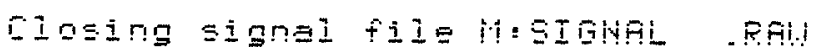

Finiti 209

HAF I9, 1901 $07: 69: 27$

Ph $\sim_{\mathrm{CN}}^{\text {OTMS }}$

racemic

SIGUAL FILE: TH:SIGIMAL PFIM

FFEAY

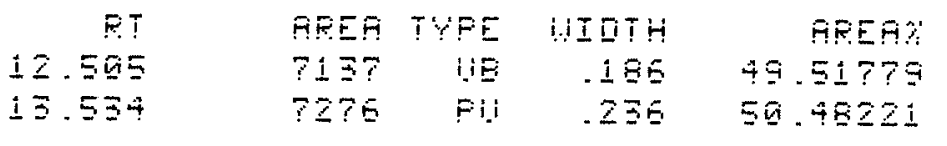

TOTFL AFEFI= I†4iJ

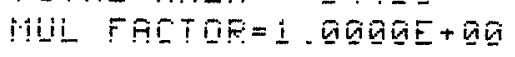



$10 J \mathrm{C}-\mathbb{I}-22 \quad 110^{\circ} \mathrm{C}$ GTA $110 \mathrm{kPa}$

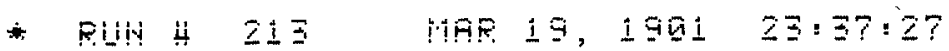

STPRT

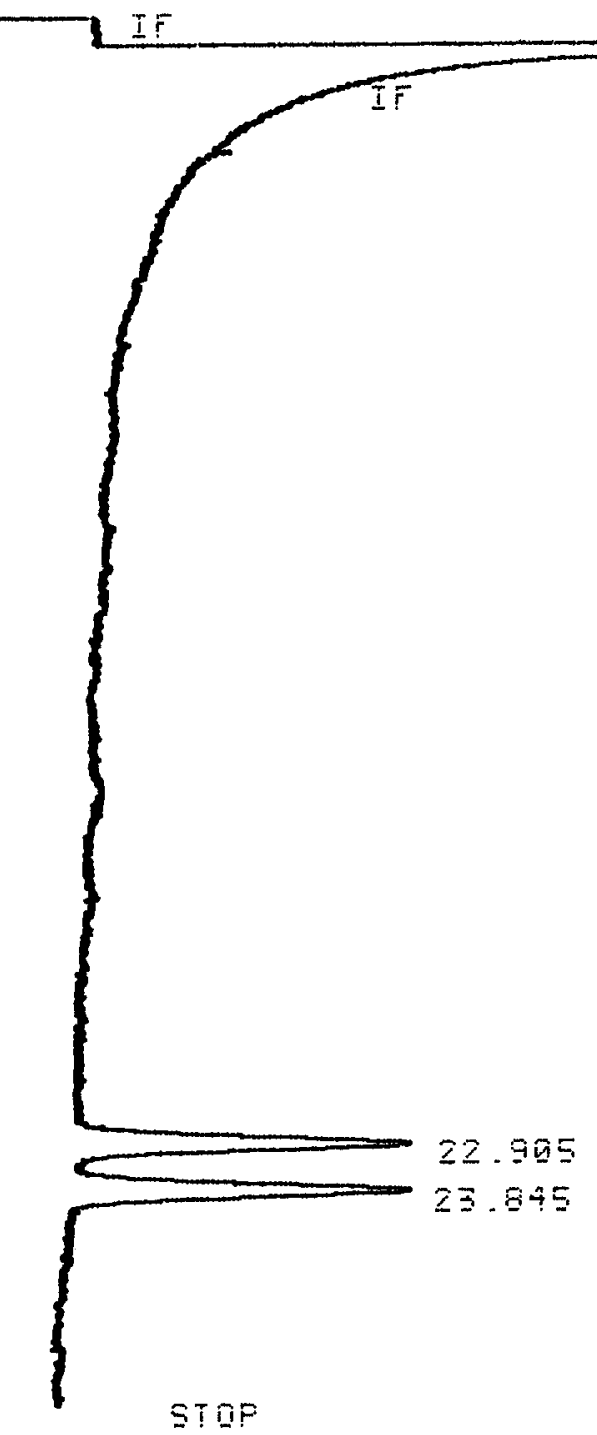

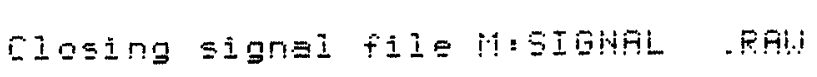

PUIH 213 HAR 19,1961 ZI:3?:Z?

$P h-\equiv{ }^{\text {OTMS }}$ CN racemic

SIGNAL TILE: H: SIGUAL RATI

TREAY:

ET AFEF TYPE IIIOTH AREAS

22.905 4258 EF .317 4?.95893

23.845 4659 PF .535 52.14117

TOTAL FFEF̂ $=8897$

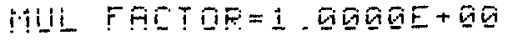



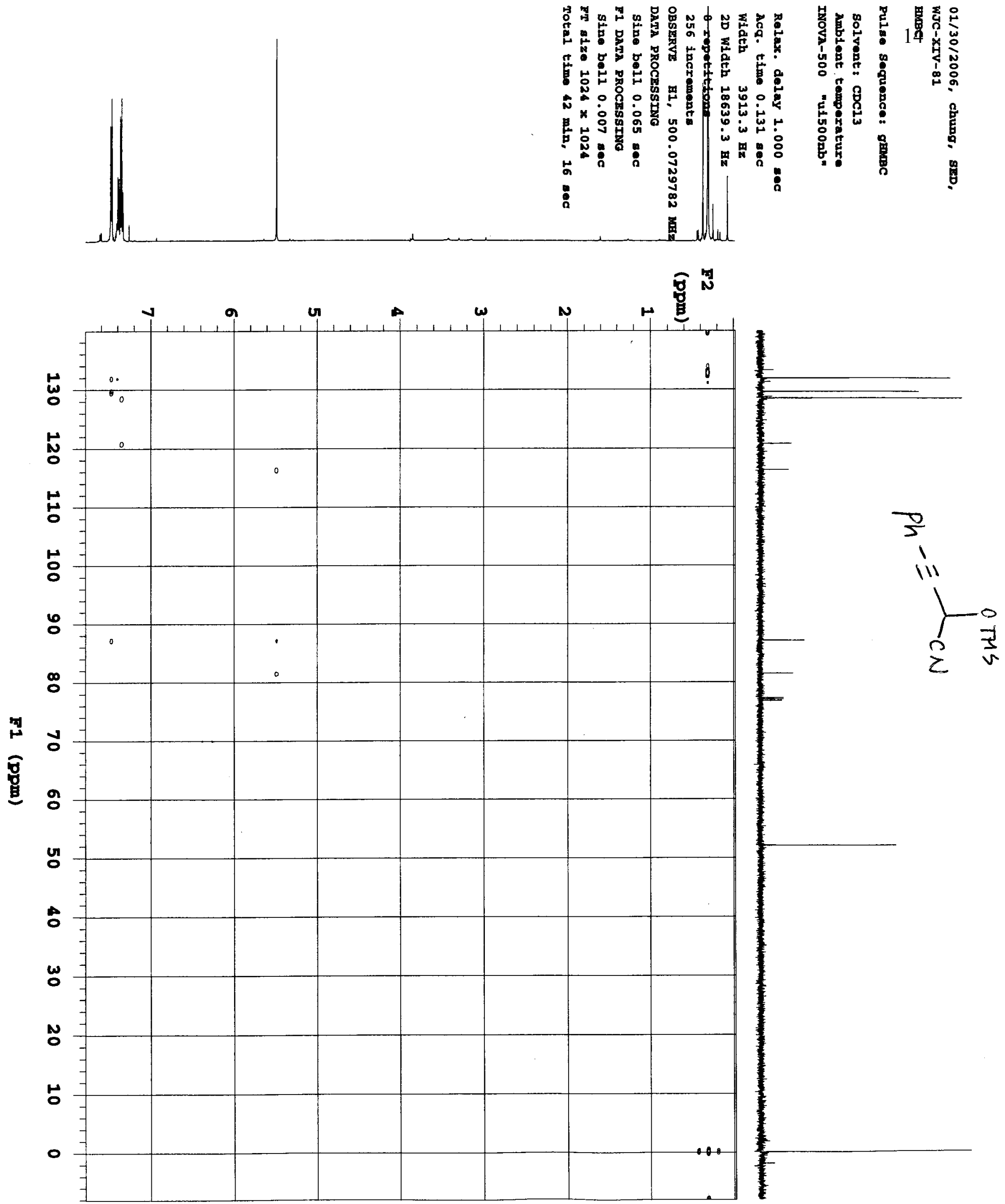

Denmark and Chung 